\title{
Feeding decisions in advanced dementia
}

\author{
RH Harwood \\ Consultant Geriatrician, Professor of Geriatric Medicine, Nottingham University Hospitals NHS Trust and University of Nottingham, \\ Nottingham
}

\begin{abstract}
When close to death, people stop eating. In neurodegenerative conditions swallowing may become unsafe, and artificial nutrition and hydration (ANH) may be proposed or requested. But nutrition is surrounded by other considerations: opportunity, help, environment, enjoyment, mood, social being and symbolic importance. Poor care or deliberate attempts to end life might also result in poor nutrition and dehydration.
\end{abstract}

Decisions about $\mathrm{ANH}$ are open to conventional ethical analysis and subject to mental capacity law. Most people with appetite or swallowing failure have advanced dementia and lack capacity. Determining someone's best interests means considering values and preferences, previous and current wishes, and requires consultation with families and other carers.

Short-term prognosis is difficult to judge in non-malignant conditions. We often do not know the views of the individual. Moreover, we are unsure if $\mathrm{ANH}$ can achieve the goals intended of it - there is little evidence that tube feeding prolongs life, prevents aspiration or improves wellbeing.

Palliative care and best practice dementia care have much in common. Open communication, good relationships with families and carers, skilled approaches to problems and respect for individuals and their diversity. Modified oral feeding will be appropriate for most; ANH is rarely appropriate, but some individuals and their families feel differently. Careful assessment for potentially treatable causes of swallowing and appetite problems, honest communication about uncertainties over prognosis and the impact of interventions and ascertainment of individuals' values and beliefs make for better care for people with dementia and better decisions about feeding.

KEYWORDS dementia, end of life care, ethics, feeding, gastrostomy, nutrition, tube-feeding

DECLARATION OF INTERESTS No conflict of interests declared.

\author{
Correspondence to RH Harwood \\ Nottingham University Hospitals \\ NHS Trust and University of \\ Nottingham \\ Nottingham NG7 2UH \\ UK
}

e-mail rowan.harwood@nuh.nhs.uk

\section{INTRODUCTION}

Decisions about feeding are emotive. Appropriate care at the end of life is as important as that at any other time, but some of the apparent 'rules' of healthcare change. Objectives shift, prognosis may be uncertain, the information required to make decisions takes effort to find and stakeholders may disagree about what is best.

This is an area where ethics, law and professional regulation meet. Ethics is the study of deciding what is right and wrong. Scottish and English mental capacity law sets out rules surrounding decision making where capacity is lacking, but interpreting these can be difficult in practice. The General Medical Council (GMC) has issued clear practical guidance on end of life care.' The Royal College of Physicians of London published a comprehensive review covering the pathophysiology of swallow, types and consequences of intervention and ethical and legal considerations. ${ }^{2}$

\section{DEMENTIA}

Dementia is a chronic neurological condition resulting in loss of memory and other mental functions. It is progressive and irreversible and will ultimately lead to death, usually from medical complications or co-morbidities rather than the dementing illness itself. In its later stages, appetite and swallowing may fail. Dementia is increasingly common with age, affecting $20 \%$ of 80 -year-olds and $30 \%$ of 90 -year-olds, and is associated with reduced life expectancy. 3.4 There is a variety of causes, including Alzheimer's disease, vascular, Lewy body and fronto-temporal dementia. In the community, Alzheimer's disease is most common, followed by vascular dementia. In hospitals, the reverse is true. 
Decision-making becomes increasingly difficult in the middle and later stages and mental capacity to consent is often lost for many medical interventions. ${ }^{5}$

There is no agreed definition of 'advanced' or 'severe' dementia. Severity is a continuum and functional ability varies with the environment, opportunity, co-morbidity, and the presence of acute illness. Features may vary greatly from one person to the next. For current purposes, 'advanced' dementia means dependency in basic activities of daily living, limited or absent verbal communication, failing ability to recognise family and problems with appetite or swallowing.

The approach of the end of life in dementia is often slow, and may extend over many months or even years. ${ }^{6,7}$ Progression can be punctuated by shorter-lived episodes of more severe decline associated with acute physical illness or injury often complicated by delirium ${ }^{8,9}$ following which recovery to the baseline trajectory may or may not occur.

\section{FEEDING PROBLEMS IN DEMENTIA}

Weight loss is common in dementia, ${ }^{10}$ due primarily to decreased energy intake rather than increased expenditure. Its physiological significance has been questioned," but most authorities hold that maintaining good nutrition is an important part of dementia care. ${ }^{12}$ Swallowing difficulties and appetite loss in dementia are associated with the end of life. ${ }^{13,14}$

There are many reasons why a person with dementia might struggle to eat properly, including loss of appetite (or hunger), poor oral health, forgetfulness, agnosia (not recognising food), apraxia (inability to use utensils, or to chew effectively), communication difficulties, anxiety, delusions (such as being poisoned), distress and associated behaviours. Help may be required with planning and preparation of food, use of altered consistencies or provision of nutrient-dense supplements, cutting up, conveying food to the mouth, encouragement to eat and keeping focused on the task. Food preferences may change and patterns of eating may deviate from social norms, such as eating a single main meal at breakfast time or snacking throughout the day. In the advanced stages of dementia notions of 'healthy eating' to prevent obesity or vascular disease should be abandoned in favour of preference, quantity and enjoyment (although for those with diabetes, avoiding crises, such as hypoglycaemia and hyperglycaemic dehydration must be considered).

Abnormalities of both voluntary and reflex swallowing appear early in the course of dementia and are typically associated with progressive weight loss. ${ }^{2}$ Of those with at least moderate dementia $40 \%$ are significantly underweight. Weight loss may be rapid during periods of acute illness.

Not all poor eating is due to dementia alone. Even at the end of life, we should assess problems for an explanation. Possible causes are sore mouth or broken teeth, lost or broken dentures, the effects of drugs (such as opiates, anti-cholinergic drugs or metformin which cause nausea, dry mouth or suppress appetite), constipation, or drowsiness. Medical causes also include hypercalcaemia, uraemia, and breathlessness. Neurogenic dysphagia can result from stroke, including progression of vascular dementia, and this may recover (within about six weeks if the time course seen in acute stroke is followed). A compromised swallow may decompensate during acute illness due to generalised muscle weakness, and may recover once the underlying illness is treated. The goal may be to keep someone 'safe' whilst recovery proceeds. However, people with dementia who are kept 'nil by mouth' may never regain oral feeding, due to loss of automatic (implicit) memory ('forgetting how to swallow').

Appetite is poor in severe depression but there should be little difficulty in distinguishing this from dementia, although it can be difficult to distinguish from hypoactive delirium. Low mood is common in dementia, and depression might make dementia appear more severe than it is. A psychiatric opinion may be needed to unravel such difficult diagnostic problems. A trial of an antidepressant is warranted in these circumstances, despite the lack of evidence of the effectiveness of antidepressant drugs for depression in dementia. ${ }^{15}$

Lack of opportunity, unmet food preference, or loss of routine such as regular meals or associated rituals (sitting at a table, social eating), fear or distraction in an unfamiliar and threatening environment may also be responsible for poor eating.

Apart from weight loss, the other problem caused by loss of safe swallowing is aspiration, which occurs in $30 \%$ of those with advanced dementia, and is often a cause of hospital admission or death.

\section{PERSON-CENTRED DEMENTIA CARE}

Best current practice in the management of people with dementia is based on 'person-centred dementia care'. This holds that people (and the institutions and systems they work in) must:

- $\quad$ value people with dementia

- individualise care taking account of neurological impairment, personality, biography, physical and mental health, retained abilities, values, beliefs and preferences 
- see problems from the perspective of the person with dementia (in particular, that challenging behaviour communicates unmet need or distress)

- recognise the importance of the social environment and relationships for wellbeing, including both family, others concerned for the person, and professionals 16,17

Person-centred care reduces distress and improves co-operation. In this schema, feeding forms an opportunity for purposeful activity, inclusion, engagement, social experience and pleasure.

\section{PALLIATIVE CARE IN DEMENTIA}

Accurate prognostication for survival is not possible in individual cases, but there are several indicators that death may not be far off. Stage 7c of the Functional Assessment Staging system (immobile, no communication, dependent in activities of daily living), ${ }^{7,18}$ hospital admission for hip fracture or pneumonia, ${ }^{19,20}$ and need for artificial feeding ${ }^{13,21}$ all suggest a prognosis of less than six months. However, almost half of people with hip fracture or pneumonia and dementia survive longer than that. Admission to an acute hospital for any reason in a person with dementia is associated with $31 \%$ six-month mortality. ${ }^{22}$ Some prognostic scores have been developed, but they have neither the sensitivity nor specificity to be useful in practice. ${ }^{23,24}$ This uncertainty should be acknowledged, and taken into account in planning (for example, by scheduling reviews).

Palliation is 'alleviation without cure'. It is not nontreatment, or withdrawal of treatment, but a reprioritisation aiming to provide comfort, relieve distress, minimise treatment burden and respect autonomy. There is no cure for dementia, and on this definition, all treatment is palliation. However, some complications and co-morbidities might be treated with curative intent, and some aspects, such as nutrition, can be considered 'supportive' rather than curative, with the aim of maintaining a state of health or slowing decline.

Palliative care defines three main principles. ${ }^{25}$

- Meticulous assessment and management of distressing symptoms

- Open communication

- Attention to psychological, social and spiritual needs.

There is complete concordance between these principles and those of person-centred dementia care.

\section{ARTIFICIAL NUTRITION AND HYDRATION}

Nutrition occupies an ambiguous position at the end of life: on one hand, overtly medical efforts to sustain nutrition clearly serve no purpose in the very last phase, and yet, prior to this, it can be seen as a basic aspect of health maintenance and social being. Failure to ensure adequate nutrition may represent poor or neglectful care, ${ }^{26}$ contributing to functional and cognitive decline, and shortening life.

There is logic to artificial nutrition and hydration if someone is malnourished and disinclined or unable to eat. Intravenous or subcutaneous fluids provide hydration but no nutrients, and provide short-term support, typically during acute illness. Tube feeding can replace that which is not taken orally, with the aim of maintaining hydration and muscle mass and avoiding micro-nutrient deficiency.

However, naso-gastric tubes are uncomfortable and not well tolerated by those who do not understand their purpose. Insertion may be resisted, they are often dislodged, and do not represent a practical option outside of hospitals (where they can be replaced if necessary). Inserting a gastrostomy, either endoscopically or radiologically, is relatively straightforward. Direct procedural mortality is $\mathrm{I}-2 \%$. Complication rates of $30-50 \%$ are often quoted, but are usually minor. Thirtyday mortality figures of a third or more are driven by the underlying illnesses for which gastrostomies are inserted rather than the procedure itself, but do raise questions about appropriateness and case selection. Ironically, one adverse effect of tube feeding is an increased risk of aspiration pneumonia, thought to be due to disordered oesophageal peristalsis and reflux of liquid feed. In any case, $500-1000 \mathrm{ml}$ of saliva is produced each day, which must be swallowed or aspirated. Feed-associated diarrhoea can be a problem but either settles with time or remits with a change of feed. It is possible for a patient to pull out his or her PEG tube but they are not uncomfortable, and can be discretely hidden under clothing, making this infrequent in practice. There are situations where tube feeding may help, including when medication is needed (such as anti-epileptic or Parkinson's disease drugs). Tube feeding might be used to supplement partial oral feeding, sometimes called 'comfort feeding', for example when oral feeding is intolerably slow, or when the desire to eat is maintained but aspiration is distressing. Oral hygiene and mouth care are especially important when little or no oral feeding occurs.

There is little evidence, however, that tube feeding achieves any of its putative benefits, although the quality of evidence is mostly poor and quite old. ${ }^{27-30}$ The best evidence comes from cohorts and case series. Two important studies used the InterRAI Minimum Data set, which is compulsory for all US nursing home residents; ; $^{3,32}$ one considered those with severe dementia, the other studied those with swallowing difficulties, and compared 
outcomes in those with and without feeding tubes. There were no differences. This finding is subject to some uncertainty - residual confounding by severity is possible (tubes are put in patients with the most severe problems, who have worse expected outcomes). The closest we have to a trial is a small American study of patients assessed and accepted for gastrostomy insertion. About half had the procedure while the families of those in the other half refused agreement; outcomes were identical. ${ }^{33}$

\section{ORAL OR HAND FEEDING}

The alternative to tube feeding is to continue oral feeding (or 'hand feeding'). Respecting food preferences, routines and non-standard timings (including during the night) can help, including more snacks, finger food, sweets and puddings. Many older people have small appetites and 'little and often' is preferred to set meals. Where human help is required, building a relationship is important, by showing interest in the person, being flexible and calm, and allowing the person with dementia as much control as possible. Distractions should be minimised, although social eating may be better than eating alone.

After excluding drug, metabolic or oral causes of anorexia or depression, appetite may be stimulated using oral steroids (e.g. $15 \mathrm{mg}$ prednisolone daily) or highdose progestagens. ${ }^{34}$ Given for I-2 weeks these can sometimes re-establish the habit of eating.

Difficulty in swallowing and aspiration risk can be minimised by following some simple rules. Assessment and advice are best given by a speech and language therapist, although relatively few specialise in caring for patients with dementia. Positioning should be upright. Feeding can be slow: pacing is important to ensure each mouthful is swallowed before the next spoonful is offered. The patient should be encouraged to use the utensil if possible or use 'hand-over-hand' guidance. A soft or pureed diet and thickened fluids are easier to swallow safely (but thickened tea and water are pretty unpalatable; fruit juice is better). Variation in (or alternation of) tastes and temperature can help; cold can be better than hot. Verbal prompts to swallow may be needed. Nutrient-dense food supplements may improve some indices of nutrition but there is little evidence that they improve function, wellbeing or survival, ${ }^{35,36}$ and they can cause adverse effects including dental decay.

Staff may be concerned about 'risks' with oral feeding, criticism about inadequate nutrition or allowing aspiration. There is no such thing as 'risk-free'; the key issues are proportionality and assessment of best interests. It is important to acknowledge that sometimes there is nothing further that can be done to improve poor eating. Patients should continue to be offered food and drink, regardless of safety concerns about aspiration. At the very end of life it is unlikely that people suffer persistent hunger or thirst, and minimal oral intake may be sufficient to provide comfort.

\section{ETHICAL ANALYSIS AND DECISION MAKING}

Our usual ethical approach, called principlism, brings together the idea that actions are judged by their consequences (benefits and burdens), and rights and duties (autonomy and justice), and this is reflected in English and Scottish mental capacity legislation. ${ }^{37}$ Prolonging life and preventing deterioration are good things in their own rights; hence the General Medical Council's 'presumption in favour of prolonging life'. However these are balanced by ideas of 'overall benefits' and the views and preferences of the patient and those close to them.'

For any medical intervention to be ethical, we must be clear what the objectives of care are ('what is this intervention intended to achieve?'). ${ }^{2}$ Long-term gastrostomy feeding is possible, but tube feeding and intravenous fluids are mostly used to support nutrition and hydration during a period of crisis such as after a stroke, surgery or cancer therapy.

A balance sheet of benefits and burdens or risks can be drawn up and it is sometimes useful to do this explicitly. Almost invariably the approach is complicated by one of two problems:

I. The principles may conflict, such as when the benefits are uncertain or come with adverse effects; and there is no clear way of resolving these conflicts.

2. Usually, in advanced dementia, the individual lacks mental capacity so to try to respect autonomy we need to assess 'best interests' or 'overall benefit'.

We can try to respect autonomy by using proxy or substitute opinions, or including considerations of values, beliefs and preferences, formalised into a best interests assessment. This requires finding out about the person's past and present wishes, values and preferences insofar as they can be determined, and consultation with families and other concerned parties. We should attempt to involve the patient in any discussion, and ascertain his or her current views, having made reasonable attempts to make information and decision making possible for them. A decision that is finely balanced will often be determined by the views of the patient, or family speaking on the patient's behalf. However, the GMC is consistent in stating that there is no obligation to provide treatment that is not in the overall interests of the patient, in the view of healthcare providers. Reaching a consensus amongst the healthcare team looking after 
the patient, or obtaining an independent second opinion is wise when there is such disagreement. Particular problems can arise where there is no family member or carer. This is remarkably common - we found $9 \%$ of acute medical admissions over the age of 70 had no family member or carer and a London study suggested a figure of $20 \%$. $^{38}$

There is published evidence from the US and Australia on what patients think, albeit with different cultures, expectations and systems. A minority would want tube feeding, fewer if it would entail using restraint, which is used in up to $70 \%$ of tube fed American nursing home patients, but most would not. Most would accept a modified consistency diet even if risk of aspiration was high. ${ }^{39}$ Most of all these data demonstrate that opinions vary, and decision making must be individualised. Family members rate the benefits of tube feeding less positively in terms of quality of life or affecting the course of the disease once they have experience of tube feeding, ${ }^{39}$ and their main complaint was about lack of information on alternatives. $^{40}$

There is a variety of alternative ethical frameworks and approaches that are relevant in dementia ${ }^{41}$ which emphasise relationships, communication and narrative. The ethics of care, perspectivism, discourse and narrative ethics highlight the uniqueness of situations, vulnerability, and caring as a disposition. The ethical solution is the one that creates and maintains healthy relationships. $A$ given situation is unlikely to yield a single 'correct' answer, since the right course of action will depend on beliefs and preferences that vary, with, amongst other things, culture and religion.

Ideally, we should all make our views about tube feeding and other life-sustaining interventions known through advance care planning, whilst mental capacity is maintained. ${ }^{42}$ This can be done through discussion with family members, writing a statement of preferences and wishes, or via legal mechanisms including advance decisions to refuse treatment or giving Lasting Power of Attorney for Health and Welfare. Enabling advance care planning is a key justification for policies to diagnose dementia earlier.

\section{WHAT TO DO IN PRACTICE}

Loss of appetite and swallow in advanced dementia may presage the end of life, but there may be reversible medical causes or short-term deterioration during acute illness or after a stroke. Maintaining good nutrition in dementia requires skill, effort, flexibility and time, and has to be seen within the context of wider efforts to deliver person-centred care. Meal times provide social interaction and should be a source of enjoyment but eating habits may change with advancing disease. Malnutrition and aspiration are the two main risks. There is little evidence that any intervention can prevent or reverse these, but poor practice probably makes them worse. Tube feeding may be proposed or requested but this will rarely be appropriate as there is little evidence to suggest that tube feeding prevents aspiration, prolongs life or improves function. Continuing careful and adapted oral feeding is probably as safe, maintains food enjoyment and social interaction during meals and will be the most appropriate course in most cases. This may not meet conventional nutritional requirements. Patients should not be made 'nil by mouth' if they wish to try to eat. A decision to insert a tube should be made after full sharing of facts and uncertainties about benefits and burdens, taking account of the patient's previously expressed or implied wishes, beliefs and values, and those of family members or others concerned for the patient. We must accept that in some cases this will result in sustained requests for tube feeding, which we should try our best to honour within available resources. Open communication and building a trusting relationship with family members is central to this process, which may be distressing to them.

\section{REFERENCES}

I General Medical Council. Treatment and care towards the end of life: good practice in decision making. Manchester: GMC, 2012. http:// www.gmc-uk.org/guidance/ethical_guidance/end_of_life_care.asp

2 Royal College of Physicians and British Society of Gastroenterology. Oral feeding difficulties and dilemmas. A guide to practical care, particularly towards the end of life. London: Royal College of Physicians, 2010. https://www.rcplondon.ac.uk/sites/default/files/ documents/oral-feeding-difficulties-and-dilemmas.pdf

3 Matthews FE, Arthur A, Barnes LE et al.A two-decade comparison of prevalence of dementia in individuals aged 65 years and older from three geographical areas of England: results of the Cognitive Function and Ageing Study I and II. Lancet 20I3; 382: I405-I2. http://dx.doi.org/10.1016/S0140-6736(I3)6I570-6

4 Xie J, Brayne C, Matthews FE et al. Survival times in people with dementia: analysis from population based cohort study with 14 year follow-up. BMJ 2008; 336: 258-62. http://dx.doi.org/I0.1 I36/ bmj.39433.6I6678.25

5 Waite J, Harwood RH, Morton IR, Connelly DJ. Dementia Care: a practical manual. OUP: Oxford, 2008.

6 Murray SA, Sheikh A. Palliative care beyond cancer: care for all at the end of life. BMJ 2008; 336: 958-9. http://dx.doi.org/I0.II36/ bmj.39535.49I238.94

7 Hughes JC, Jolley D, Jordan A, Sampson EL. Palliative care in dementia: issues and evidence. Advances in Psychiatric Treatment 2007; I3: 25 I-60. http://dx.doi.org/I0.I I 92/apt.bp.106.003442

8 Mukadem N, Sampson EL. A systematic review of the prevalence, associations and outcomes of dementia in older general hospital inpatients. Int Psychogeriatr 20II; 23: 344-55. http://dx.doi. org/10.1017/S1041610210001717

9 Whittamore K, Goldberg S, Gladman JR, Bradshaw LE, Jones RG, Harwood RH. The diagnosis, prevalence and outcome of delirium in a cohort of older people with mental health problems on general hospital wards. Int J Geriatr Psychiatry 20I4; 29: 32-40. http://dx.doi.org/I0.1002/gps.396I 
10 Mitchell SL, Teno JM, Kiely DK et al. The clinical course of advanced dementia. N Engl J Med 2009; 36I: 1529-38. http://dx. doi.org/I0.1056/NEJMoa0902234

II Hoffer LJ. Tube feeding in advanced dementia: the metabolic perspective. BMJ 2006; 333, I2/4-15. http://dx.doi.org//0.1/36/ bmj.3902I.785197.47

12 Skills for Care \& Skills for Health. Common Core Principles For Supporting People With Dementia: A guide to training the social care and health workforce. Leeds/Bristol: Skills for Care \& Skills for Health, 20I I. http://www.dh.gov.uk/prod_consum_dh/groups/dh_ digitalassets/documents/digitalasset/dh_127587.pdf

13 Watson R, Deary IJ.A longitudinal study of feeding difficulty and nursing interventions in elderly patients with dementia.J Adv Nurs 1997; 26: 25-32.

14 Grant MD, Rudberg MA, Brody JA. Gastrostomy placement and mortality among hospitalized Medicare beneficiaries. JAMA 1998; 279; 1973-6.

15 Banerjee S, Hellier J, Dewey M et al. Sertraline or mirtazapine for depression in dementia (HTA-SADD): a randomised, multicentre, double-blind, placebo-controlled trial. Lancet 201 I; 378: 403-II. http://dx.doi.org/I0.1016/S0I40-6736(II)60830-I

16 Brooker D. Person Centred Dementia Care: Making Services Better. London: Jessica Kingsley, 2006.

17 Harwood RH. Dementia for hospital physicians. Clin Med 2012; 12 35-9.

18 Sachs GA, Shega JW, Cox-Hayley D. Barriers to excellent end-oflife care for patients with dementia. J Gen Intern Med 2004; 19 : 1057-63.

19 Morrison RS, Siu AL. Survival in end-stage dementia following acute illness. JAMA 2000 284; 47-52.

20 Holmes J, House A. Psychiatric illness predicts poor outcome after surgery for hip fracture: a prospective cohort study. Psychol Med 2000; 30: 921-9.

2I Alvarez-Fernández B, Garcia-Ordoñez MA, Martinez-Manzaranes $C$ et al. Survival of a cohort of elderly patients with advanced dementia, nasogastric tube feeding as a risk factor for mortality. Int J Geriatr Psychiatry 2005; 20: 363-70.

22 Bradshaw LE, Goldberg SE, Lewis SA et al. Six-month outcomes following an emergency hospital admission for older adults with co-morbid mental health problems indicate complexity of care needs. Age Ageing 2013; 42: 582-8. http://dx.doi.org//0.1093/ ageing/aft074

23 Yourman LC, Lee SJ, Schonberg MA, Widera EW, Smith AK Prognostic indices for older adults: a systematic review. JAMA 2012; 307: 182-92. http://dx.doi.org/10.1001/jama.20II.1966

24 Porock D, Parker-Oliver D, Petroski GF, Rantz M. The MDS Mortality Risk Index: The evolution of a method for predicting 6-month mortality in nursing home residents. BMC Res Notes 2010, 3: 200. http://dx.doi.org// 0.1 186/1756-0500-3-200

25 Hanks G, Cherny NI, Christakis NA et al (eds). Oxford Textbook of Palliative Care. 4th edn. Oxford: OUP, 20I I.
26 Care Quality Commission. Dignity and nutrition inspection programme: National overview. London: Care Quality Commission, 20Il. http://www.cqc.org.uk/sites/default/files/ documents/20III007_dignity_and_nutrition_inspection_ report_final_update.pdf

27 Candy B, Sampson EL, Jones L. Enteral tube feeding in older people with advanced dementia: findings from a Cochrane systematic review. Int J Palliat Nurs 2009; 15: 396-404.

28 Finucane TE, Christmas C, Travis K. Tube feeding in patients with advanced dementia: a review of the evidence. JAMA 1999; 282: 1365-70.

29 Gillick MR. Rethinking the role of tube feeding in patients with advanced dementia. N Engl J Med 2000; 342: 206-210.

30 American Geriatrics Society Ethics Committee and Clinical Practice and Models of Care Committee. American Geriatrics Society Feeding Tubes In Advanced Dementia Position Statement. J Am Geriatr Soc 2014. http://dx.doi.org/ I0.I I I / jgs. 12924

3I Mitchell SL, Kiely DK, Lipsitz LA. The risk factors and impact on survival of feeding tube placement in nursing home residents with severe cognitive impairment. Arch Intern Med 1997; 157: 327-32.

32 Mitchell SL, Kiely DK, Lipsitz LA. Does artificial enteral nutrition prolong the survival of institutionalized elders with chewing and swallowing problems? J Gerontol A Biol Sci Med Sci 1998; 53: M207-13.

33 Murphy LM, Lipman TO. Percutaneous endoscopic gastrostomy does not prolong survival in patients with dementia. Arch Intern Med 2003; 163: I351-3.

34 Palliative Care Formulary. http://www.palliativedrugs.com/palliativecare-formulary.html

35 Milne AC, Avenell A, Potter J. Meta-analysis: protein and energy supplementation in older people. Ann Intern Med 2006; 144: 37-48. http://dx.doi.org/I0.7326/0003-48I9-I44-I-200601030-00008

36 Avenell A, Handoll HH. Nutritional supplementation for hip fracture aftercare in older people. Cochrane Database Syst Rev 2010; I: CD001880. http://dx.doi.org//0.1002//465/858. CD001880.pub5

37 Beauchamp TL, Childress JF. Principles of Biomedical Ethics. 7th edn. New York: OUP, 2013.

38 Sampson EL, Blanchard MR, Jones L, Tookman A, King M. Dementia in the acute hospital: prospective cohort study of prevalence and mortality. Br J Psychiatry 2009; 195:61-6. http://dx.doi.org/I0.1192/ bjp.bp. 108.055335

39 O'Brien LA, Siegert EA, Grisso JA et al. Tube feeding preferences among nursing home residents.J Gen Intern Med 1997; 12: 364-7I.

40 Ladas SD, Triantafyllou K, Liappas I et al. Percutaneous endoscopic gastrostomy: adequacy and quality of information given to decision makers. Dig Dis 2002; 20: 289-92.

4I Hughes J, Baldwin C. Ethical Issues in Dementia Care. Making Difficult Decisions. London: Jessica Kingsley, 2006.

42 Royal College of Physicians of London. Advance care planning. Concise Guidance to Good Practice Series, number 12. London: Royal College of Physicians, 2009. https://www.rcplondon.ac.uk/sites/ default/files/documents/acp_web_final_21.01.09.pdt 